\title{
A PRODUÇÃO DO DISCURSO SOBRE O PATRIMÔNIO CULTURAL MILITAR: OS USOS E DESUSOS DOS TOMBAMENTOS DAS FORTALEZAS NO BRASIL
}

\author{
Alessandro Pereira Oliveira ${ }^{1}$ \\ Luana de Carvalho Silva Gusso ${ }^{2}$ \\ Felipe Borborema Cunha Lima ${ }^{3}$
}

Resumo: Este artigo é parte de uma pesquisa de dissertação em andamento vinculada ao Programa de Pós-Graduação em Patrimônio Cultural e Sociedade da Universidade da Região de Joinville (Univille) cujo tema é a análise do discurso patrimonial militar mobilizado para a candidatura do conjunto de fortificações brasileiras a patrimônio mundial da Organização das Nações Unidas para a Educação, a Ciência e a Cultura (Unesco). Nessa linha, o presente texto busca analisar a produção do discurso sobre o patrimônio cultural militar com base nas diversas estratégias realizadas pelo exército brasileiro desde os primeiros tombamentos das fortalezas, em 1937, até as atuais formas de gestão patrimonial e cultural implementadas pela instituição em 2017. A metodologia é a pesquisa documental e bibliográfica. Como resultado, constatou-se que o discurso produzido sobre o patrimônio cultural militar é mobilizado e adaptado ao conceito de cultura na contemporaneidade, mesmo sendo eivado de patriotismo e com sentimento de nacionalidade.

Palavras-chave: Patrimônio cultural. Tombamento. Fortificações. Exército. Unesco.

\section{THE PRODUCTION OF NARRATIVE DISCOURSE ABOUT THE MILITARY CULTURAL HERITAGE: THE USES AND DISUSES OF PROTECTION LIST OF THE BRAZILIAN'S FORTRESSES}

\begin{abstract}
This paper is part of an ongoing dissertation research linked to the Postgraduate Program in Cultural Heritage and Society of the University of the Region of Joinville (Univille), whose theme is the analysis of the military patrimonial discourse mobilized for the candidacy of the set of Brazilian fortresses to the world heritage of the United Nations Educational, Scientific and Cultural Organization (Unesco). In this sense, the present text seeks to analyze the production of the discourse on the military cultural heritage based on the different strategies carried out by the Brazilian army from the first nominations of protection list of fortresses in 1937 to the current forms of patrimonial and cultural management implemented by the institution in 2017. The methodology is documentary and bibliographic research. As a result, it was found that the narrative discourse produced on the military

\footnotetext{
${ }^{1}$ Mestrando no Programa de Pós-Graduação em Mestrado em Patrimônio Cultural e Sociedade da Univille. Email: alessandro.oliver@hotmail.com

2 Professora do MPCS, Programa de Mestrado em Patrimônio Cultural e Sociedade da Univille, e do curso de Direito. Pós-Doutora em Democracia e Direitos Humanos pela Universidade Coimbra. Email: lu_anacarvalho@yahoo.com.br

${ }^{3}$ Doutor em Turismo. Bolsista PNPD- Pós- DOC no Programa de Mestrado em Patrimônio Cultura e Sociedade da Univille. Email: felipebcl2@hotmail.com
} 
cultural heritage is mobilized and adapted to the concept of contemporary culture, even though it is surrounded by patriotism and a sense of nationality.

Keywords: Cultural heritage. Protection list. Fortresses. Army. UNESCO.

\section{LA PRODUCCIÓN DEL DISCURSO SOBRE EL PATRIMONIO CULTURAL MILITAR: LOS USOS Y DESUSO DE LA CONSERVACIÓN DE LAS FORTALEZAS EN BRASIL}

Resumen: Este artículo es parte de una encuesta de disertación en curso vinculada al Programa de Postgrado en Patrimonio Cultural y Sociedad de la Universidad de la Región de Joinville (Univille) cuyo tema es el análisis del discurso patrimonial militar movilizado para la candidatura del conjunto de fortificaciones brasileñas el patrimonio mundial de la Organización de las Naciones Unidas para la Educación, la Ciencia y la Cultura (Unesco). En esta línea, el presente texto busca analizar la producción del discurso sobre el patrimonio cultural militar con base en las diversas estrategias realizadas por el ejército brasileño desde los primeros tumbamientos de las fortalezas, en 1937, hasta las actuales formas de gestión patrimonial y cultural implementadas por la institución en 2017 La metodología es la investigación documental y bibliográfica. Como resultado, se constató que el discurso producido sobre el patrimonio cultural militar es movilizado y adaptado al concepto de cultura en la contemporaneidad, aun siendo eivado de patriotismo y con sentimiento de nacionalidad.

Palabras clave: Patrimonio cultural. Conservación. Fortificaciones. Ejército. UNESCO.

\section{Introdução}

Este artigo tem como objetivo analisar a produção do discurso sobre patrimônio cultural militar com base nas diferentes estratégias adotadas pelo exército brasileiro no tombamento das fortalezas gerenciadas por essa instituição militar no período entre 1937 até 2017. Para tanto, o texto foi organizado por meio de marcadores discursivos em que se abordou como o exército brasileiro se organizou e se preparou diante da política cultural nacionalista do Estado Novo. Nesse sentido, problematizaram-se os usos e desusos do patrimônio cultural fortificado e tombado como instrumento de legitimação dos fortes tombados no período da política cultural do governo getulista. Em seguida, destacou-se, em um momento após 1964, durante o governo militar, a criação das diretorias vinculadas ao setor cultural do exército, bem como o tratamento estratégico dado ao patrimônio cultural. Nessa seara, as fortificações tombadas ganharam nova conotação no jogo político do exército brasileiro.

Fundamentado em uma abordagem interdisciplinar, o presente texto foi construído metodologicamente mediante uma análise documental na qual foram verificados documentos 
oficiais, como leis, portarias, decretos e normatizações do exército, vinculados ao seu setor cultural, como também cartas patrimoniais que sustentaram a candidatura das fortificações. Esse método de investigação científica auxiliou na compreensão do passado histórico dessas fortificações, além de servir de base para entender as políticas culturais já ocorridas no Brasil entre o período delimitado no artigo. Outra técnica utilizada foi a pesquisa bibliográfica, que contribuiu cientificamente na delimitação e construção do tema abordado. Ainda, foi explorado o banco de dados digital de fortificações (fortalezas.org), que enriqueceu a pesquisa fornecendo algumas informações do patrimônio cultural fortificado aqui pesquisado.

Dessa forma, o presente artigo apresenta-se estruturado em quatro sessões, seguidas pelas considerações finais. Na primeira sessão, nomeada "O tombamento e o espírito nacionalista de 1937”, foi apresentada a mobilização do discurso patrimonial referente aos primeiros tombamentos das fortalezas brasileiras no florescer do Decreto n. ${ }^{\circ}$ 25/1937, que institui o tombamento. Eivado pela política nacionalista do período Vargas e sustentado por um ideal patrimonial de identidade nacional do período, o patrimônio militar responde à lógica cultural reinante. A segunda sessão, "A mobilização de forças", destaca como o exército passou a mobilizar o patrimônio cultural como um ativo discursivo de sua política cultural e institucional. Por sua vez, a terceira sessão, “Os anos 1970”, reflete sobre o uso do discurso patrimonial e das políticas culturais do exército (e das fortalezas) no contexto dos governos militares brasileiros. Por fim, a quarta sessão, intitulada "A redemocratização dos anos 1990”, problematiza a mobilização dos órgãos oficiais do exército e de seus setores culturais em um período pós-redemocratização, em que o patrimônio cultural militar, especialmente o tombamento de suas fortalezas, tem sido mobilizado como expoente histórico e arqueológico fundamental da sociedade brasileira, entrando em uma espécie de corrida patrimonial ao selo da Organização das Nações Unidas para a Educação, a Ciência e a Cultura (Unesco) como patrimônio mundial da humanidade. Nesse sentido, interroga-se como os militares têm mobilizado e utilizado o seu discurso patrimonial como sustentáculo na candidatura do conjunto de fortificações a patrimônio mundial da humanidade.

\section{O tombamento e o espírito nacionalista de 1937}


A década de 1930 foi um período de grandes mudanças no escopo político e cultural no Brasil. Implementado por Getúlio Vargas, o regime do Estado Novo erigiu uma identidade nacional e um slogan para assegurar a conjuntura político-ideológica do regime a partir da criação e afirmação da identidade nacional, do "homem brasileiro". Com isso, o Estado elaborava, conforme o seu viés ideológico, "a construção simbólica da nação", e reconhecia a necessidade de adotar um elemento de integração nacional que fosse capaz de garantir ao Estado, o apoio político que era preciso a fim de proporcionar mais poder de persuasão principalmente em relação às classes populares (CHUVA, 2003).

O nacionalismo adotado e utilizado como política de Estado teve grande influência na área cultural da época, e foi nesse período que o patrimônio histórico e cultural teve seus pilares erguidos no Brasil. Em 1937, o governo criou o Serviço do Patrimônio Histórico e Artístico Nacional (SPHAN). Com tal iniciativa, o Estado institucionalizou a preservação do patrimônio histórico cultural no país e, por meio dessa nova entidade, assumia a função de proteger o patrimônio brasileiro criando normatizações e dispositivos para identificação, seleção, conservação e restauração dos bens culturais de natureza material (PEREIRA, 2012). Para Fonseca (2005, p. 17), no Brasil, a temática do patrimônio surgiu "alicerçada nos pressupostos do modernismo enquanto expressão de modernidade". Ainda nessa constituição de patrimônio nacional, a autora afirma:

\begin{abstract}
A constituição de patrimônios históricos e artísticos nacionais é uma prática característica dos Estados modernos que, através de determinados agentes, recrutados entre os intelectuais, e com base em instrumentos jurídicos específicos, delimitam um conjunto de bens no espaço público. Pelo valor que lhes é atribuído enquanto manifestações culturais e enquanto símbolos da nação, esses bens passam a serem merecedores de proteção, visando à sua transmissão para as gerações futuras. Nesse sentido, as políticas de preservação se propõem a atuar, basicamente, no nível simbólico, tendo como objetivo reforçar uma identidade coletiva, a educação e a formação de cidadãos. Esse é, pelo menos, o discurso que costuma justificar a constituição desses patrimônios e o desenvolvimento de políticas públicas de preservação (FONSECA, 2005, p. 21).
\end{abstract}

Segundo Chuva (2003, p. 14), com a criação do SPHAN, o governo estado-novista, por intermédio do patrimônio histórico e artístico nacional, "homogeneizava e civilizava" a população dando ênfase aos heróis e às datas comemorativas selecionadas pelas elites do país, porém não representava somente essa classe, mas todos os brasileiros de forma igual 
(MAGALHÃES, 2004). No que tange à inserção do Nacionalismo no cenário cultural do país, segundo Gellner (1993), toda cultura deve ter seu próprio Estado, e tais culturas ditas como estatais disputam entre si. Nessa perspectiva, "uma sociedade móvel, atomizada e igualitária, com uma cultura padronizada que seja letrada e superior, e cuja manutenção, disseminação e fronteiras sejam protegidas por um Estado. Dito de maneira ainda mais sucinta: uma cultura, um Estado; um Estado, uma cultura" (GELLNER,1993, p.79).

A promulgação do Decreto-Lei n. ${ }^{\circ}$ 25, de 1937, foi outro marco basilar no processo de preservação do patrimônio no Brasil. Ele estabeleceu o tombamento, ou seja, uma ferramenta jurídico-administrativa que, segundo Kersten (2000, p. 49-50), “é uma ação ritualizada, que retira o bem do cotidiano e o reveste de significações, participando agora de outra narrativa e cronologia".

No escopo da política patrimonial do governo getulista, segundo Pereira (2012), o tombamento foi uma das iniciativas essenciais do projeto do governo para a construção da identidade nacional por intermédio do patrimônio cultural. Na ótica de Rodrigo Melo Franco de Andrade, primeiro diretor do SPHAN, o processo de tombamento constituía o "ato declaratório da incorporação de um bem ao patrimônio histórico e artístico nacional" (ANDRADE, 1987, p. 51).

Aquilo que se denomina Patrimônio Histórico e Artístico Nacional - por ser espólio dos bens materiais móveis e imóveis aqui produzidos por nossos antepassados, com valor de obras de arte erudita e popular ou vinculados a personagens e fatos memoráveis da história do país - é o documento de identidade da nação brasileira (ANDRADE, 1987, p. 51).

Por meio desse processo de ressignificação patrimonial, o tombamento ratificava a prática seletiva que marcaria as peculiaridades do chamado patrimônio nacional. A modernização e a nacionalização eram duas bases essenciais que sustentavam essa nova visão do campo patrimonial no Brasil, além de serem utilizadas como modos que o governo tinha de suplantar os infortúnios internos nacionais e o retardo do país, em analogia a outras nações, principalmente europeias. As estratégias de preservação do patrimônio histórico nacional atendiam, inicialmente, a algumas das recomendações expressas nas Cartas de Atenas (1931 e 1933), sobretudo no que tangia à valorização do monumento mediante a criação de áreas verdes e perspectivas que facilitassem sua apreciação (PELEGRINI, 2006). Nos primeiros anos de operação do SPHAN, a justificativa que amparava as primeiras iniciativas do órgão era a "realização geral do tombamento dos monumentos a fim de evitar a evasão e a 
destruição das obras, objetos de arte e de história, dignos de nossa tradição e apreço" (PELEGRINI, 2006, p. 18).

No tabuleiro do jogo ideológico estado-novista, é fundamental salientar que todo esse aparato de iniciativas políticas no âmbito cultural elaboradas pelo regime varguista, como a criação do SPHAN, a lei do tombamento e a personificação do "homem brasileiro", inclusive a inserção e valorização da cultura popular (folclore, tradições populares) - porém ainda não incorporadas nas práticas de preservação cultural -, foram peças fundamentais para a propaganda do governo, que possuía um órgão, criado em 1939, responsável pela propagação dos valores estado-novistas: o Departamento de Imprensa e Propaganda (DIP), com enfoque maior nas classes de trabalhadores.

Essa construção do imaginário sociopolítico da nação ancorado pelo patrimônio nacional ocorre, no campo teórico, com base no conceito nomeado por Hobsbawm e Ranger (2006) de "tradições inventadas", pois no solo ideológico estatal da época esse conceito foi peça-chave no projeto de idealização simbólica da nação brasileira. Ainda sobre a ideia das tradições inventadas, os autores descrevem:

Entende-se um conjunto de práticas, normalmente reguladas por regras tácitas ou abertamente aceitas; tais práticas, de natureza ritual ou simbólica, visam inculcar certos valores e normas de comportamento através da repetição, o que implica, automaticamente; uma continuidade em relação ao passado (HOBSBAWM; RANGER, 2006, p. 271).

No âmbito mundial, no campo do patrimônio, algumas mudanças e transformações já estavam ocorrendo nesse período. A Carta de Atenas foi concebida ainda na década de 1930 e tinha, segundo Pelegrini (2006, p. 3), a finalidade de abordar "a relação entre a preservação do patrimônio histórico e a crescente expansão das cidades".

Após a Segunda Guerra Mundial, o patrimônio cultural alcançou outra escala. Com a grande destruição das cidades e de seus respectivos patrimônios, o mundo passou a ter outro olhar sobre seu patrimônio. Com isso, surgiu a necessidade de estabelecer uma política que de fato viesse a preservar e valorizar os bens culturais dos povos. Em 1954, a Convenção de Haia (1954) foi o primeiro acordo transcontinental visando exclusivamente à proteção do patrimônio cultural. Tal documento proporcionou uma proteção bem mais abrangente do que 
a de seus predecessores. Embora se restringisse somente às ações das forças armadas durante a guerra, era aplicado a todos os conflitos armados com ocupações bélicas de qualquer natureza (BISCHOFF, 2004).

O patrimônio cultural fortificado militar no Brasil tem relação intrínseca com o Nacionalismo, pois se encaixava diretamente, por causa de suas características arquitetônicas, no projeto do patrimônio nacional arquitetado pela política cultural do Estado Novo. O exército, naquele período, era um dos braços de sustentação do regime varguista e possuía grande influência no governo, e os militares eram impulsionados pelas ideias positivistas de "ordem e progresso", slogan-chave da proclamação da república. Segundo Carvalho (2005, p. 96), a partir de 1930, “as Forças Armadas, particularmente o exército, se viram instaladas no centro do poder nacional de maneira muito mais decisiva". Em 1937, consolidava-se a concepção de que o exército "coexistiria com a estrutura do Estado e seria seu elemento dinâmico" (CARVALHO, 2005, p. 66).

Uma das personagens principais do exército nesse período e grande aliado de Vargas foi o ministro da Guerra Góis Monteiro, um dos responsáveis pela mudança de postura da instituição no que tange à participação da força militar na política. Góis achava o sistema político da década de 1930, cujo esteio era o liberalismo, antes da implementação do Estado Novo, inadequado, como também criticava as elites dirigentes, acusando-as de incapazes de integrar o país e de não ter visão nacional. Segundo Carvalho (2005, p. 67), "o Estado Novo veio coroar e levar às últimas consequências o modelo visualizado por Góis Monteiro". Principalmente eliminando a política partidária da sociedade, os militares consolidaram-se, pelo lado político, como "a garantia da base social das elites tradicionais e, pelo lado econômico, a promoção dos interesses da burguesia industrial emergente" (CARVALHO, 2005, p. 69).

\section{A mobilização de forças}

Para refletirmos sobre a mobilização do patrimônio militar no Brasil, é fundamental que recorramos ao século XIX e ao início do XX, pois foi nesse período que algumas instituições culturais militares foram criadas, como

O real arquivo militar de 1808; o museu do Exército 1808; Museu do Exército, de 1865; a Biblioteca do Exército, de 1881; a Revista do Exército Brasileiro, de 1882; a Revista A Defesa Nacional, de 1913; e o Instituto de 
Geografia e História Militar do Brasil, de 1934 vêm sendo, identificados como as raízes da cultura no Exército (MATTOS, 2018, p. 38).

Berkowicz (2013) salienta que, com esse cenário, o movimento institucional do exército da época possibilitou a construção de uma realidade que se fez por meio da seleção de memórias que recriavam uma instituição de raízes sólidas e dotadas de uma unidade. $\mathrm{Na}$ ótica de Carvalho (2005, p. 66), foi nesse período que ocorreu a concepção de que a sociedade “deveria se abrir ao Exército e que a Instituição deveria estar fechada à sociedade”, ideia que ganhou força particularmente durante o Estado Novo, empenhada por setores mais conservadores das Forças Armadas.

O Exército chegara ao centro do poder político, alegando ser a encarnação das aspirações nacionais, estar acima dos interesses regionais e partidários. Apesar disso, era impotente quando se tratava de influenciar a população, tanto no que se referia à preparação militar, à disciplina dos corpos, como diria Foucault, quanto à disciplina das mentes, essencial para seu projeto (CARVALHO, 2005, p. 78).

Nessa perspectiva, algumas iniciativas foram adotadas para insular o exército da sociedade, particularmente no que tangia à seleção e formação do oficialato. É essencial ressaltarmos a mudança no plano simbólico da criação, por exemplo, de um "conjunto de símbolos que expressava o pertencimento dos cadetes a uma tradição vinculada ao que se considerava serem valores nacionais mais profundos" (CARVALHO, 2005, p. 85). "A abertura da sociedade ao Exército, o fechamento da organização, a formação de um grupo hegemônico de oficiais, constituíam parte da estratégia de fortalecimento da corporação militar para consolidar e ampliar a posição de poder que conquistara dentro do Estado" (CARVALHO, 2005, p. 87).

Nesse sentido, voltando ao patrimônio com a política de tombamento adotada pela SPHAN, em 1938 diversos fortes de arquitetura militar foram tombados pelo órgão. Nas palavras de Homero (2013, p. 14), logo nos primeiros anos de atuação do órgão foram inscritas no Livro do Tombo "vinte e quatro fortificações, para o mesmo era de grande interesse do SPHAN preservar esses monumentos de maior valor social", protegendo-os por lei contra a destruição ou adulteração. Segundo Bogéa e Schlee (2017, p. 28), os fortes tombados no primeiro ano da SPHAN foram: 
Forte Velho do Cabedelo (PB); Fortim Caetano Madeira (RJ); Forte Orange, Forte Buraco, Forte Do Brum, Forte das Cinco Pontas, Forte do Pau Amarelo todos em Pernambuco; Portão da Fortaleza de São João (RJ); Fortaleza Santo Antônio Ratones (SC); Fortaleza Santa Cruz de Anhatomirim (SC); Forte Santana (SC); Fortaleza de São José da Ponta Grossa (SC); Fortaleza de Caçapava (RS); Fortaleza de Santa Catarina do Cabedelo (PB); Fortaleza do Morro de São Paulo (BA); Forte São Lourenço (BA); Forte de Paraguaçu (BA); Forte de Gragoatá (RJ); Fortaleza Nossa Senhora dos Prazeres (PR); Fortaleza da Conceição (RJ); Forte Gamboa, Santa Maria, Santo Antônio da Barra e de São Marcelo todos em Salvador na Bahia.

Os fortes eram vistos, pelo órgão de proteção, como um bem de grande valor simbólico, porém gozavam de menos interesse do ponto de vista mercadológico, por serem antigos e não terem uso prático (HOMERO, 2013). Algumas fortificações, como a de Santa Cruz, localizada na cidade do Rio de Janeiro, foram tombadas, mas suas atividades militares de defesa continuaram funcionando. Essa era a categoria patrimonial que se enquadrava no projeto de patrimônio nação. Ainda para Homero (2013, p. 15), no que tangia aos tombamentos desses monumentos, "a decisão dos funcionários do SPHAN daquela época, de tombar os fortes, foi sábia: uma visão estritamente utilitária implicaria no seu abandono quando não mais tivessem uma função prática”.

Seguindo essa linha de raciocínio, vemos no Gráfico 1 o número de tombamentos do patrimônio cultural fortificado no primeiro período de funcionamento do SPHAN. O que chama a atenção é a quantidades de bens tombados em 1938.

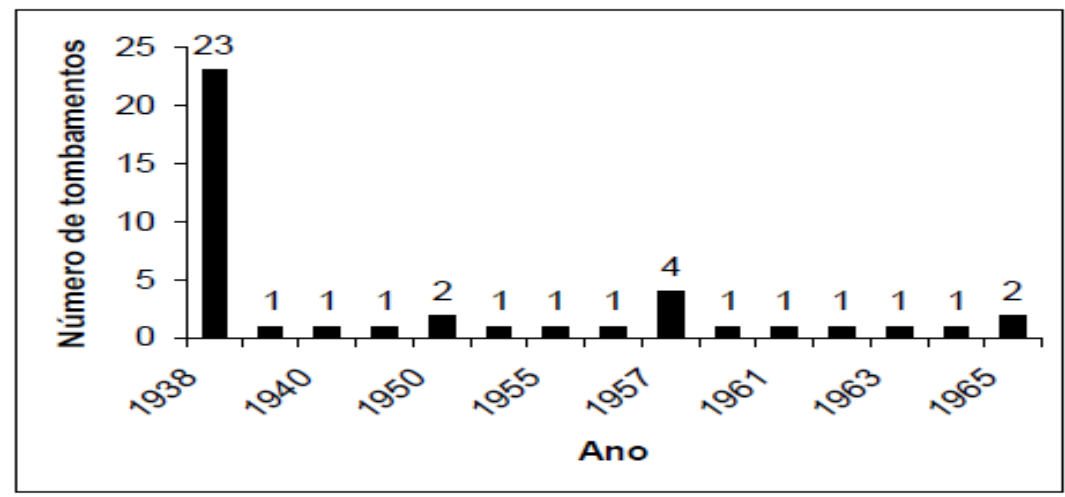

Gráfico 1 - Número de fortes tombados no Brasil entre 1938 e 1967

Fonte: Nakamuta (2009, p. 105)

Nos primeiros anos de atuação do SPHAN, a justificativa que alicerçava as intervenções para o tombamento dos bens era a "realização geral do tombamento dos 
monumentos a fim de evitar a evasão e a destruição das obras, objetos de arte e de história, dignos de nossa tradição e apreço" (ANDRADE, 1987, p. 24). No que tange aos monumentos de arquitetura militar, segundo Nakamuta (2009), em análise dos processos de tombamento do período de 1938 a 1940, nenhum dos processos possuía alegações oportunas quanto ao seu valor atribuído para fins de tombamento. Em alguns casos, como, por exemplo, o Forte São João de Bertioga, no litoral paulista, mencionou-se a necessidade emergencial de obras para conservação e/ou restauração. Ou seja, essa afirmativa corrobora o discurso de Rodrigo Melo Franco de Andrade, primeiro gestor do SPHAN, como citado anteriormente, de que muitas dessas fortificações foram tombadas com o intuito de evitar a destruição do bem. Outra observação a ser considerada nos processos de patrimonialização do patrimônio militar entre 1938 e 1940 é o fato de a grande parte deles ter sido de caráter ex-ofício, conforme já previsto no art. 5. ${ }^{\circ}$, capítulo II, do Decreto-Lei n. ${ }^{\circ}$ 25, de 1937.

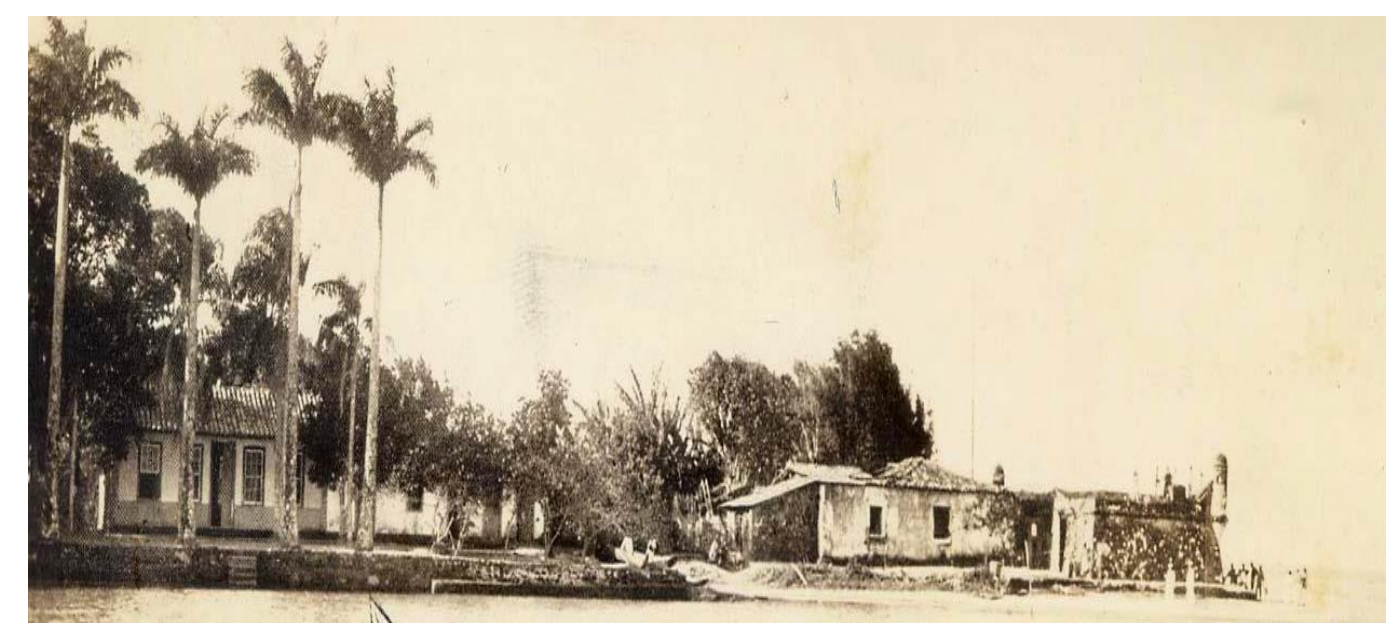

Figura 1. Vista geral do Forte São João em Bertioga-SP

Fonte: Arquivo Central do IPHAN (Levantamento fotográfico de José Reis, 1938)

No período pós-Segunda Guerra Mundial, no cenário internacional, o patrimônio alcançou outra escala no que tange a sua preservação, conservação e valorização. Primeiramente, com a criação da Unesco, em 1945, outros documentos foram confeccionados como instrumentos para a salvaguarda do patrimônio: a Convenção de Haia e a Carta de Veneza, de 1964. Esta última foi um marco na salvaguarda do patrimônio material, e a Convenção da Unesco de 1972 foi o divisor de águas no campo patrimonial, por meio do 
reconhecimento da importância da diversidade e do próprio conceito de patrimônio da humanidade.

O patrimônio militar no Brasil, bem como as fortificações militares, passou por um processo de transformação, pois muitas fortificações estavam obsoletas para o serviço de defesa de artilharia de costa, em razão da modernização dos sistemas defensivos, além de ultrapassadas no que se refere a armas de defesa. Muitos desses locais viraram espaços vazios e de alto custo de manutenção. Desativados como praças de guerra, os fortes passaram a depender, para sua preservação, de sua conversão para novos usos, porém havia alguns empecilhos para a ressignificação dessa categoria patrimonial, marcada pela própria natureza de sua arquitetura, caracterizada por não ser aberta ao meio exterior.

Por intermédio do Regulamento das Fortificações Costeiras n. ${ }^{\circ}$ 26.959, de 27 de julho de 1949, instituído pelo General Dutra e revogado pelo presidente Getúlio Vargas, em 1952, o exército buscou uma solução para os fortes que não possuíam sua operacionalidade de defesa. Nessa normatização, as fortificações costeiras e unidades móveis de artilharia de costa podiam ser categorizadas em três situações: em serviço; temporariamente fora de serviço; ou definitivamente fora de serviço (MATTOS, 2018). Para os padrões da época, os fortes deveriam ser apropriados a outras destinações de interesse do Ministério da Guerra ou entregues ao SPHAN.

Nesse período, as fortificações pouco a pouco foram perdendo sua função original, passando a ser administradas por órgãos responsáveis pelo setor cultural. Nesse sentido, os militares alinharam-se ao discurso de salvaguarda do patrimônio cultural da nação, defendendo o tombamento como ferramenta jurídico-administrativa, para assegurar a preservação desse bem e colocá-lo como parte das representações históricas da nação. Nessa perspectiva, segundo Homero (2013, p. 27), “as Forças Armadas aceitaram o pequeno desconforto que a supervisão do [Instituto do Patrimônio Histórico e Artístico Nacional] IPHAN geraria com o tombamento, pois havia uma compreensão da importância da criação de símbolos nacionais, tal como tinha ocorrido durante a Revolução Francesa”.

Um fator primordial que ampara esse argumento, como citado anteriormente, foi o elevado número de fortes tombados pelo SPHAN no primeiro período da gestão de Rodrigo Melo de Andrade, porém esse cenário em termos patrimoniais se modificaria principalmente por conta das convenções que ocorreriam e também por uma nova conceituação de patrimônio 
cultural em âmbito global, atingindo todas as categorias dos bens patrimoniais, fosse cultural, fosse natural.

\section{Os anos 1970}

O Brasil em 1964 vivia uma ditadura militar que perdurou por 21 anos, e, de grandes influenciadores dos governos passados, os militares agora eram os protagonistas do cenário político nacional. O golpe militar tinha como objetivo, no discurso dos militares, segundo Silva (2002 p. 43), “o combate à ascensão comunista e o restabelecimento da ordem em todas as esferas da sociedade (política, social, econômica)". O regime marcou um período, como na grande maioria dos governos autocráticos, notabilizado pela supressão dos direitos constitucionais, censura, perseguição política, repressão aos opositores do regime, esvaziamento do legislativo e limitação do poder judiciário. Os militares, para se legitimarem no poder, traçaram estratégias e investiram com o seu aparato ideológico, delineado em grande parte pelos ideólogos da Escola Superior de Guerra (ESG), na educação cívica e na cultura, pois elas seriam fundamentais para a aceitação e legitimação do regime.

Segundo Rezende (2013. p. 40), “o regime militar considerava que o campo psicossocial se constituía num solo enormemente fértil para se travar uma verdadeira batalha no processo de busca de sua legitimidade”. A cultura que se discutirá mais à frente, neste artigo, será ferramenta essencial para a promoção, o controle e a legitimação do regime.

No âmbito da cultura, o patrimônio cultural insere-se em um "contexto mais amplo sendo levado a refletir sobre novas possibilidades de fronteiras ou clivagens, motivadas por outras dimensões de pertencimento que não à nação" (CHUVA, 2012, p. 17). Ou seja, a conceituação do patrimônio nação deu lugar à diversidade cultural, fazendo com que o patrimônio no universo das identidades locais e das singularidades dialogasse com o nacional (ABREU, 2007). Um marco, nesse período, que trouxe a ótica de universalidade ao patrimônio foi a Convenção da Unesco de 1972, a primeira convenção referente ao patrimônio mundial. Nesse documento, as políticas voltadas ao campo patrimonial ficaram em bastante evidência no mundo.

Com o reconhecimento da necessidade da importância da diversidade, essa convenção considerou que os sítios declarados como patrimônio mundial pertenciam a toda a humanidade e não seriam mais vistos como uma "propriedade comum, mas de interesse de todos os povos" (ZANIRATO, 2010, p. 12). Essa chancela da Unesco concede aos sítios 
reconhecidos como patrimônio mundial um atrativo cultural e econômico, o que de certa forma chamou a atenção dos países-membro da Organização das Nações Unidas (ONU) para a questão patrimonial e foi fundamental para a produção das políticas públicas de salvaguarda do patrimônio cultural naquele período. O pensamento da Unesco passou a figurar que o patrimônio não somente preconizasse os valores "de civilização", ou da cultura erudita, mas sim "a universalidade da cultura, através do respeito pelas culturas específicas" (POULOT, 2009 , p. 225). De certa forma, essa convenção contribuiu de maneira grandiosa, em todo o globo, para a confecção das políticas de salvaguarda do patrimônio em todas as suas categorias.

No campo do patrimônio cultural militar, foi na década de 1970 que o exército iniciou o processo de institucionalização da cultura nos seus quadros. Em 1973, mediante o Decreto n. ${ }^{\circ}$ 71.823, a instituição criou a Diretoria de Assuntos Especiais, Educação e Desportos (Daed). Ela era incumbida de orientar, coordenar e controlar as atividades relacionadas a olimpíadas, competições e preparo de equipes do exército destinadas ao desporto, como também os assuntos especiais vinculados à cultura dos militares do exército. Com a criação desse órgão, que era ligado à cultura, a sua relação com o desporto nas Forças Armadas sempre foi muito forte (MATTOS, 2018).

Nesse período foi inaugurado o Centro de Documentação do Exército (CDocEX), segundo o Decreto n. ${ }^{\circ} 76.813$, de 16 de dezembro de 1975 , cuja principal finalidade era realizar o planejamento, a orientação e o controle das atividades relacionadas à administração do patrimônio do exército em Brasília, além da documentação, da história e do patrimônio histórico-cultural do exército.

Segundo Mattos (2018), ambos os departamentos foram os precursores das futuras estruturas organizacionais que iriam balizar de modo sistemático o campo da cultura nas décadas seguintes no exército. A Daed, primeiro órgão do organograma do exército a tratar de assuntos culturais, em 1975 teve suas atividades extintas pelo presidente Ernesto Geisel.

No campo cultural, sob a tutela do regime militar, foi criado o Plano Nacional de Cultura (PNC), encabeçado pelo ministro da Educação e Cultura Ney Braga. Os militares, com o lançamento desse plano, reconheciam a necessidade de inserir a cultura no seu plano de governo, porém isso era visto como estratégia, segundo Silva (2002, p. 51), “em ter um apoio das classes de intelectuais e artistas vinculados à cultura estes que tinha um posicionamento político mais coligado a esquerda". É fundamental ressaltarmos que o governo Geisel, assim 
como o de seus antecessores, apesar da repressão, nunca abriu mão dos mecanismos institucionais que lhe davam sustentação e legitimidade.

No escopo desse plano de cultura, percebemos a influência da ESG na sua elaboração. Conforme Silva (2002, p. 185), foi com base nas orientações doutrinárias da escola que o PNC se fundamentou, "trazendo a idéia da preservação da identidade nacional e da renovação cultural”. Ainda sobre esse fato, a instrumentalização da cultura é outra característica intrínseca tanto na doutrina da ESG como no PNC, o que sustenta a ideia da influência dos militares esguianos no plano, como expõe Silva (2002, p. 190)

No PNC exalta-se o papel da cultura na preservação das características da personalidade nacional que ser quer manter - hábitos, costumes, valores, tradições, etc. e ao mesmo tempo, na renovação de aspectos dessa personalidade, através da incorporação e absorção de novos traços culturais. Também na doutrina esguiana, a cultura é parte da expressão psicossocial do poder nacional.

Nesse período, houve significativa ampliação das ações do Ministério da Educação e Cultura no campo cultural: a criação do Conselho Nacional de Direito Autoral (CNDA) e do Conselho Nacional de Cinema (Concine), a reforma da Empresa Brasileira de Filmes (Embrafilme), a criação da Fundação Nacional de Arte (Funarte) e o lançamento da Campanha de Defesa do Folclore Brasileiro.

No âmbito do exército, em 1979, por meio da Portaria ministerial n. ${ }^{\circ} 2.449$, de 27 de setembro, com influência das mudanças na área da cultura na esfera nacional, elaboraram-se as "normas para a utilização dos arquivos, bibliotecas e museus do Exército por parte de historiadores e outros estudiosos" (BRASIL, 1979) que possibilitavam condições de acessibilidade do público mediante regras estabelecidas. O texto dessa portaria, porém, proporcionaria dúbia interpretação, pois, segundo Mattos (2018), ao mesmo tempo em que legitimava e permitia o acesso a historiadores e outros acadêmicos e garantia liberdade de estudo por eles, condicionava o acesso a um ponderado processo para adquirir a credencial de segurança. Com isso, os militares deixavam clara sua desconfiança em relação ao público civil no que tange ao manuseio dos seus arquivos, reforçando assim, com essa postura, o isolamento que o setor cultural da instituição possuía na época.

Entre 1967 e 1979, foram cinco as fortificações tombadas pelo IPHAN: "Forte Coimbra-MS, Forte Santo Antônio-MA, Forte Santa Tecla-RS, Baluarte de São Luís, e os remanescentes da fortificação do sítio de Trindade em Recife-PE” (BOGÉA; SCHLEE, 2017, 
p. 29). Esse pequeno número revela o contraste com a política inicial do órgão em seus primeiros anos de existência, que realizou o processo de tombamento de 40 fortificações. Segundo Bogéa e Schlee (2017), um dos motivos que justifica essa diminuição acentuada dos processos de tombamento no período pós-gestão de Rodrigo Melo de Andrade é que esse tipo de patrimônio não foi muito priorizado pela gestão do órgão no período, que estava sob administração do arquiteto Renato Soeiro. É essencial frisarmos, porém, que a ideia de patrimônio nação que se iniciou no Estado Novo e que era uma política cultural institucionalizada também contribuiu de forma acentuada com o elevado número de tombamento das fortificações, que eram vistas como símbolo da nacionalidade brasileira.

Em 1980, em função do redesenho do organograma administrativo do Exército, foi criada a Diretoria de Assuntos Culturais, Educação Física e Desportos (Daced), pelo Decreto n. ${ }^{\circ}$ 84.608, de 31 de março, que nasceu na Diretoria de Ensino e Pesquisa (DEP). Por intermédio dessa nova organização militar, a instituição tentava centralizar as atividades culturais. O escopo estrutural da Daced abrangia atividades ligadas à equitação, educação física e editoração, apontando para uma visão, segundo Mattos (2018, p. 48), ainda "disfuncional” da área cultural. Ou seja, com o acúmulo de atividade culturais, esportivas e literárias, a atividade cultural foi colocada em segundo plano. Corroborando com essa afirmação, grande parte das ações da Daced limitava-se à convocação dos atletas e da própria seleção do exército para as disputas de campeonatos (MATTOS, 2018), e as atividades correlacionadas ao patrimônio cultural militar não eram valorizadas pelo comando da instituição.

Outra situação que evidencia certo isolamento do setor cultural do exército se materializa na própria falta de mediação técnica do IPHAN para assuntos correlacionados à salvaguarda do seu patrimônio histórico e cultural. Nesse período, a instituição já possuía patrimônios fortificados tombados pelo órgão federal, porém nem na própria Daced existia um setor responsável para exercer esse diálogo. Conforme Mattos (2018), cada organização militar tinha de se alinhar nessa condição. Isto é, prestava contas diretamente ao IPHAN, quando necessário, e a preservação dos bens patrimoniais funcionava de forma descentralizada, pois cada organização militar gestora possuía certa autonomia.

Em 1985, o exército transferiu o seu museu histórico da casa de Deodoro, na zona norte carioca, para o Forte de Copacabana, o que de certa maneira contribuiu para que nos dias de hoje esse patrimônio cultural de arquitetura militar seja um dos lugares mais visitados 
da cidade do Rio de Janeiro. Em seu discurso oficial, o primeiro diretor salienta a importância da mudança do museu para um sítio fortificado e também a função dele para o resgate da história da instituição:

É, pois, com grande satisfação, que registramos os primeiros passos de uma realidade. Uma realidade que enfrentará o desafio de fazer com que o Exército Brasileiro possa dispor de um Museu Histórico que se torne, pela preservação de sua memória e pela amostragem dinâmica de sua história, um elo com o público em geral, contribuindo para o conhecimento e o estudo da nossa história (TEIXEIRA, 2016, p. 48).

Apesar da criação em 1973 de alguns órgãos vinculados ao setor cultural e ao patrimônio cultural, ainda não havia sido publicamente instituída no exército uma política de preservação ou de salvaguarda de seu patrimônio cultural, fosse tombado, fosse imaterial. Esse cenário iria se modificar por conta do alargamento do conceito de patrimônio cultural trazido pela Constituição Federal de 1988 e, nos anos 2000, da criação de uma política cultural que institucionalizou a salvaguarda do patrimônio cultural militar. Contudo é essencial salientar que muitos fortes que estavam sob administração do exército eram utilizados, nesse período, como aquartelamento pela instituição e, outros, além de estarem em desuso, foram “abandonados" pela instituição, como ocorreu, por exemplo, no Forte de Nossa Senhora dos Prazeres, localizado na Ilha do Mel, em Paranaguá (PR), tombado em 1938, desmobilizado em 1954 pelos militares e abandonado até o ano de 1995, período no qual o IPHAN iniciou sua restauração (TEIXEIRA, 2014).

No fim dos anos 1980, o patrimônio cultural brasileiro passaria por importantes modificações, com a ampliação do seu conceito mediante sua constitucionalização em 1988 pelo art. 216 da Constituição Federal. A proteção jurídica dos bens culturais no Brasil recebeu novo status pelos dispositivos que versam sobre direitos culturais, meio ambiente e patrimônio cultural. O texto constitucional veio influenciado por uma tendência mundial de mobilização em prol do direito ao patrimônio cultural. Para Pelegrini (2006, p. 21), a Carta Constitucional de 1988 "representou avanços na luta em prol da cidadania e das políticas preservacionistas" e abriria as portas para uma nova ótica na salvaguarda do patrimônio cultural brasileiro. A Carta Magna de 88 alargou as ferramentas que protegem os bens culturais com a interrupção do exclusivismo do tombamento como instrumento para os bens culturais (SOARES, 2009). 


\section{A redemocratização dos anos 1990}

Na década de 1990 na esfera do patrimônio cultural militar ocorreram diversas mudanças, influenciadas por uma nova forma de enxergar o patrimônio cultural, em razão principalmente do art. 216 da Carta Magna. Por causa de uma nova modificação na estrutura administrativa do exército brasileiro, surgiu a Diretoria de Assuntos Culturais (DAC), pelo Decreto n. ${ }^{\circ}$ 99.735, de 27 de novembro de 1990, órgão técnico-normativo do Departamento de Ensino e Pesquisa (DEP). Esse órgão seria um avanço no que tange aos assuntos que envolvem a cultura no âmbito da instituição. Essa organização militar tinha por missão “controlar, preservar, conservar, recuperar, restaurar e divulgar o patrimônio cultural material e imaterial de interesse da história do exército brasileiro" e funcionaria com uma "proposta de sistematização e formulação de diretrizes normativas para o setor cultural do exército brasileiro" (BRASIL, 1990).

Nesse período, em 1994, o General Zenildo Gonzaga Zoroastro de Lucena criou o Dia do Exército, rememorando "a batalha de Guararapes 19 de abril de 1648" (CASTRO, 2002, p. 37). Esse militar teve essa iniciativa, além de também abrir alguns patrimônios fortificados sob a tutela do exército à população, porém essa "abertura" seria normatizada e consolidada em 2000.

Os anos 2000 começaram movimentados no setor cultural militar, primeiramente com a publicação das Normas para Elaboração, Aprovação e Execução de Programas e Projetos Culturais (Portaria n. ${ }^{\circ}$ 30, de 5 de junho de 2000, do DEP), que tinha a finalidade de regular procedimentos concernentes a programas e projetos culturais vinculados ao exército. Logo depois, foi promulgada a portaria para a abertura das fortificações à visitação pública (Portaria n. ${ }^{\circ}$ 615, de 13 de novembro de 2000), cujo escopo era regular a abertura das fortificações militares do exército à visitação pública, possibilitando, com isso, a divulgação à população brasileira da imagem de um exército que se preocupava com a preservação de seu patrimônio histórico. É importante dizer que a preservação era um dos objetivos principais dessa iniciativa, lembrando que muitos desses fortes já eram tombados pelo IPHAN e que algumas dessas fortificações, antes mesmo de tal normativa, foram abertas à visitação pública, como as da cidade de Niterói, que "receberam cerca de 70 mil visitantes em 1998" (MATTOS, 2018, p. 173). 
Porém essa mesma norma que estabelece diretrizes para visitação da população civil instrui aos gestores desses sítios fortificados que há assuntos evitados à imprensa, como a utilização, em qualquer época, das instalações da fortificação como presídio e com "qualquer acontecimento ali ocorrido e cuja divulgação não seja positiva para a imagem do Exército, desde que não seja um fato histórico marcante" (BRASIL, 2000). Mediante esse documento, podemos perceber que, ao mesmo tempo em que o discurso da instituição é de aproximação da sociedade civil por intermédio do patrimônio cultural fortificado, ele restringe o que, na leitura dos militares, não foi um fato de relevância para a historicidade da instituição.

Nesse sentido, resgatamos Foucault (2003) para essa reflexão. Em uma sociedade fechada à produção do discurso, essa mesma produção é ao mesmo tempo controlada, selecionada e redistribuída. Em 2002, o exército elaborou a sua política cultural e a diretriz estratégica do seu sistema cultural através da Portaria nº 614, de 29 Out. Essa política cultural foi alocada como um "subsistema do setor de ensino da instituição", sendo uma das responsáveis para a mudança da posição que a cultura alcançaria dentro da instituição e também pela valorização da salvaguarda do patrimônio de arquitetura militar que estava sob sua administração. A seguir, estão elencados os objetivos gerais da política cultural da força militar

Projetar a imagem do Exército a partir dos seus valores culturais; divulgar as realizações da Instituição nos campos da obtenção do conhecimento, das artes e das manifestações comportamentais; preservar, restaurar, recuperar e divulgar o patrimônio material histórico, artístico e cultural do Exército; Incentivar a preservação das tradições, da memória e dos valores morais, culturais e históricos do Exército; estimular, no público interno, o interesse pela preservação do meio-ambiente e pela melhoria da qualidade de vida; maximizar a difusão, nos públicos interno e externo, de sentimentos de nacionalidade, patriotismo, amor fraterno e mútua compreensão social (BRASIL, 2000, p. 60).

$\mathrm{Na}$ perspectiva desses objetivos, podemos encontrar semelhança com o Plano Nacional de Cultura de 1975 no que tange à evocação dos sentimentos patrióticos e nacionalistas que norteiam a política atual da instituição, além de rememorar o projeto de patrimônio nação adotado na política cultural do Brasil no período getulista. Com os assuntos culturais em efervescência no meio militar e com uma política e diretrizes que fundamentam e dão força ao setor cultural do exército, a instituição, que teve esse setor um pouco afastado do 
meio civil, tem como duas das atuais orientações sua aproximação e interação com a população em geral

O Exército é parte da Sociedade Brasileira, por ela criado e nutrido, e para ela são dedicadas as suas ações. Por conseguinte, a harmonia entre as entidades militares e as civis deverá ser total, com seus integrantes interagindo em ambiente de cortesia recíproca e irmanados para atingir os anseios do povo brasileiro (BRASIL, 2000, p. 61).

Outro ponto fundamental para a atual posição que o patrimônio cultural alcança dentro da instituição, ganhando novo status na maior instituição militar do Brasil, foi a criação da Fundação Cultural Exército Brasileiro (Funceb) no ano 2000. Trata-se de uma entidade civil, com personalidade jurídica de direito privado, sem fins lucrativos, com autonomia administrativa, financeira e patrimonial que tem no seu bojo de finalidades:

I - desenvolver ações relacionadas a atividades de natureza cultural, desportiva, educacional, de comunicação social, de preservação do meio ambiente e de assistência social desenvolvidas pelo Exército Brasileiro; II promover os valores centrais das instituições militares brasileiras; III promover o inter-relacionamento entre militares, suas famílias e os diferentes segmentos da sociedade em geral, por intermédio de projetos e atividades cívicas e culturais; IV - recuperar e preservar o patrimônio histórico e artístico do Exército Brasileiro; V - divulgar a história, o patrimônio artístico militar e outros aspectos da cultura militar brasileira (FUNCEB, 2012).

Segundo o seu Estatuto (FUNCEB, 2012), sua criação foi motivada a fim de permitir melhor acesso ao acervo do patrimônio histórico e cultural da instituição; o comando do exército apoiou a iniciativa do empresariado brasileiro de constituí-la. Essa fundação tem contribuído para a dinamização do patrimônio cultural militar por meio da revista Da Cultura, lançada em 2001, publicando editoriais sobre o patrimônio cultural fortificado de todo o país e dando notoriedade à valorização dessa categoria patrimonial. Segundo Mattos (2018, p. 91), "ao longo dos anos a revista Da Cultura fortaleceu a visibilidade do campo cultural. Capas e artigos sobre fortificações, reportagens sobre espaços culturais". Um fato que chama a atenção e que está até mesmo nas diretrizes da política cultural do exército como orientação é a celebração de convênios com a Funceb para viabilizar o apoio aos projetos e às atividades culturais da força militar. Com isso, vemos a intensa influência que essa entidade civil tem sobre o setor cultural do exército. 
No ano 2008, em razão da busca para o aprimoramento dos assuntos culturais e também pela posição que a cultura alcançou nos últimos anos na instituição, o exército modificou seu organograma, e a DAC passou a ter uma nova designação: Diretoria do Patrimônio Histórico e Cultural do Exército (DPHCEX) por intermédio do Decreto n. ${ }^{\circ}$ 6.710, 23 dez. 2008. Essa nova diretoria, no bojo de suas atribuições, procurou o alinhamento desta com os demais órgãos nacionais responsáveis pela salvaguarda do patrimônio, fruto de diálogos entre os militares e os órgãos civis coligados ao patrimônio cultural. A seguir se tem uma das atribuições da DPHCEX: "Ligar-se com o Ministério da Cultura, por intermédio do Instituto do Patrimônio Histórico, Cultural e Artístico Nacional (IPHAN) e do Departamento de Museus (DEMU), e com outros órgãos públicos federais, estaduais ou municipais, para tratar de assuntos culturais" (DPHCEX, 2016)

Com toda essa reestruturação no campo patrimonial do exército, o patrimônio cultural de arquitetura militar crescia em notoriedade, e reforçava-se a ideia de que era fundamental para o próprio desenvolvimento da cultura no âmbito militar que as normativas estivessem em consonância com as legislações no que tange ao setor cultural do país. Nessa perspectiva, o General Darke, chefe do Estado-maior de exército no ano de 2009, cita esse enquadramento do setor cultural com as demais entidades federais de cultura:

O Exército é uma instituição brasileira e, assim sendo, não pode se eximir do cumprimento da legislação vigente, nem agir de modo dissonante com o resto do país. Dessa forma, os atos normativos que têm efeito no âmbito da Força são elaborados no sentido de atender ao previsto na Lei e às necessidades específicas da Instituição. O Exército, por intermédio da Diretoria do Patrimônio Histórico e Cultural do Exército, subordinada ao Departamento de Educação e Cultura do Exército, interage com órgãos do Ministério da Cultura, como o Instituto do Patrimônio Histórico e Artístico Nacional (IPHAN) e o Museu Nacional; com Secretarias Estaduais e Municipais de Cultura e, por vezes, com instituições privadas, por intermédio da Fundação Cultural Exército Brasileiro (FUNCEB), visando a aprimorar, atualizar e aplicar as normas internas em consonância com a legislação nacional (TRAJANO, 2009, p. 7).

O discurso de salvaguarda do patrimônio de arquitetura militar estava cada vez mais disseminado entre os militares, sustentado pelo crescimento do turismo nos fortes sob a administração da instituição, após estes terem sido abertos ao público; por uma mudança na sua estrutura organizacional, com a criação de uma diretoria técnica que contribuiu diretamente para que o patrimônio fosse percebido de outra forma; e, ainda, com a criação da 
Funceb, que auxiliou com o financiamento, por meio de parcerias público-privadas, de obras de restauração e conservação de alguns fortes. Um dos maiores exemplos dessa mobilização em prol da preservação está na candidatura do conjunto de fortificações a patrimônio mundial da Unesco, que tem criado interfaces institucionais para a salvaguarda desse tipo de bem patrimonial entre militares, acadêmicos, profissionais do campo do patrimônio e gestores de fortes. Os militares têm buscado elaborar projetos culturais que ajudam diretamente na captação de recursos para a contribuição do processo de preservação do seu patrimônio histórico e cultural.

Um desses programas é nomeado de Mecenas e "busca possibilitar e incentivar a colaboração de pessoas físicas e jurídicas aos projetos culturais do Exército Brasileiro" (DPHCEX, 2016), por meio da destinação de parte do imposto de renda ao governo federal para programas culturais de interesse do exército, aos moldes da Lei Rouanet. Atualmente, o exército prevê em seu Plano Estratégico (PEEx) estratégias a serem adotadas pelo comando da instituição e medidas para sua execução no decorrer do triênio 2016-2019, inserindo a preservação do seu patrimônio histórico cultural nas ações de criação de espaços culturais. É fundamental salientar que a instituição vê a atividade no campo cultural como "influente estímulo ao sentimento de patriotismo e ao orgulho de nacionalidade" (CCOMSEx, 2010) características essas intrínsecas aos militares que mobilizam o campo cultural dentro da instituição com base nesses pilares.

Como citado anteriormente, a candidatura do conjunto de fortificações a patrimônio mundial tem fixado parcerias entre os ministérios da Cultura, do Turismo e da Defesa. Em abril de 2017, no Seminário Internacional de Fortificação, os entes públicos envolvidos na candidatura assinalaram um documento nomeado de a Carta do Recife. Nessa carta de intenções, as partes envolvidas articularam planos de trabalho integrados, estabeleceram modelos de gestão e valorização turística e cultural, como também a promoção do uso sustentável para assegurar a preservação do bem, garantindo sua manutenção e conservação, e outras diretrizes que os participantes acharam pertinentes para a gestão.

O exército é gestor de oito do conjunto de 19 fortes que são candidatos a patrimônio mundial e tem apoiado a promoção de eventos para o debate do tema com assídua participação da academia. Um deles foi o Encontro Internacional de Fortificações e 
Patrimônio Militar - Gestão, Inovação e Turismo em Fortificações (Icofort) Rio 20174, que contou com a presença de pesquisadores, estudantes e gestores de fortificações não só do Brasil, como de outras fortalezas do mundo.

Importante lembrar que o Comitê Científico Internacional sobre Fortificações e Patrimônio Militar pertence ao Conselho Internacional de Monumentos e Sítios (Icomos) ${ }^{5}$ e auxilia anualmente esse órgão consultivo da Unesco na avaliação das propostas da lista a patrimônio mundial, na categoria fortificações e patrimônio militar.

As fortalezas da candidatura são: os fortes Príncipe da Beira (RO) e Coimbra (MS), que delimitavam os marcos da fronteira oeste do território brasileiro; o Forte de São José do Macapá (AP), como marco das definições da fronteira norte; as fortificações do Ratones e de Anhatomirim, da Ilha de Santa Catarina, que marcam a divisa sul; o Forte dos Reis Magos, em Natal (RN), o extremo leste; as fortificações de Pernambuco - fortes das Cinco Pontas, Brum e Santa Cruz de Itamaracá/Orange -, marcando as lutas contra a Companhia das Índias; os fortes da Baía de Todos os Santos - São Marcelo, Monte Serrat, Santa Maria, São Diogo e Santo Antônio da Barra - e da Baía da Guanabara - fortalezas Santa Cruz e São João -, definindo as defesas das duas capitais do Brasil colônia; e as fortificações da Barra de Santos, incluindo os fortes do Canal de Bertioga, Barra Grande e São João, assinalando a defesa do porto que escoou a maior parte da riqueza produzida no Brasil (BRASIL, 2017). Segue abaixo a ilustração dos fortes selecionados por estado.

\footnotetext{
${ }^{4}$ Ocorreu na cidade do Rio de Janeiro no ano de 2017 e teve como um dos principais assuntos debatidos no evento a candidatura do conjunto de fortificações brasileiras a patrimônio da humanidade.

${ }^{5}$ Associação civil não governamental ligada à ONU e órgão consultivo da Unesco.
} 


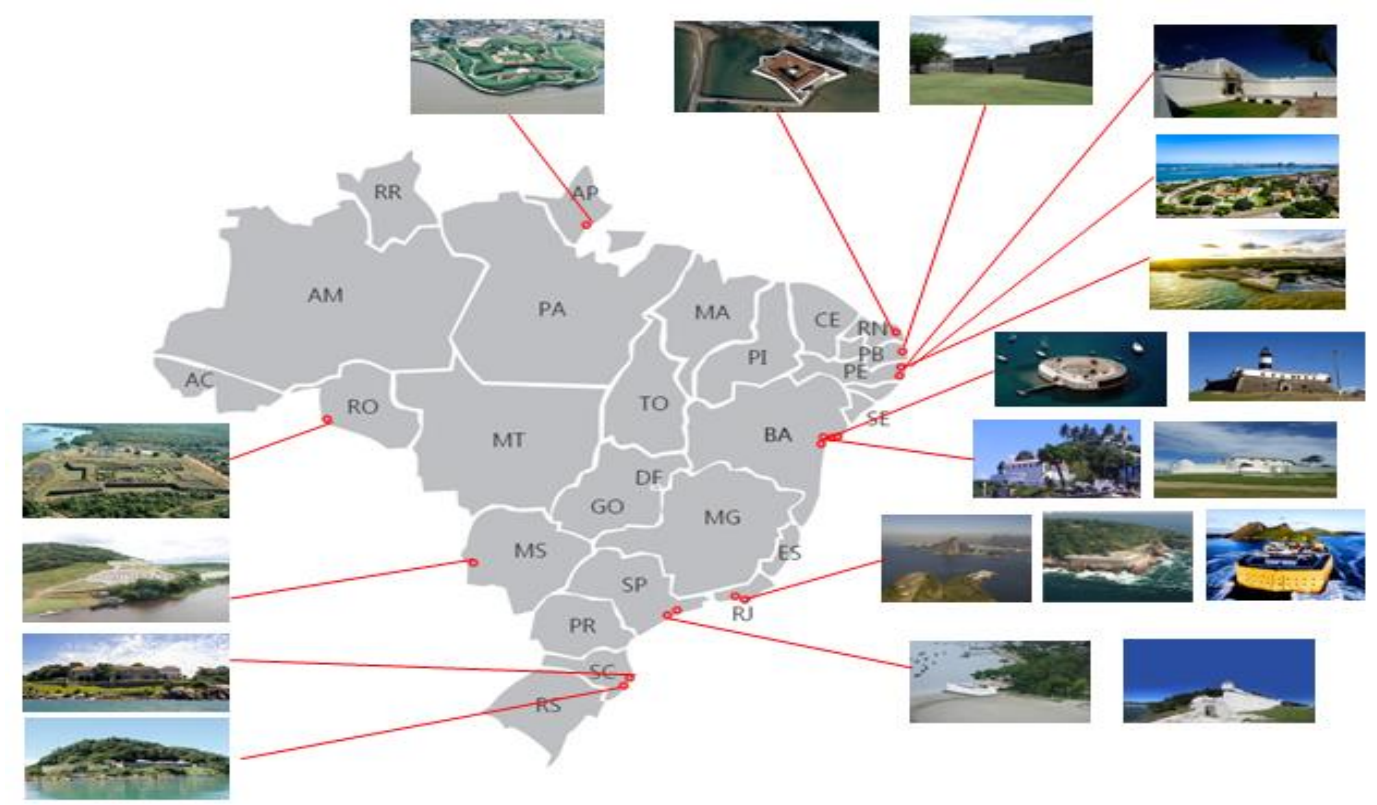

Figura 2 - Fortes que estão na lista indicativa brasileira a patrimônio mundial da Unesco Fonte: elaborado pelo autor a partir das fotos disponíveis em http://www.fortalezas.org

O conjunto de fortes foi selecionado por uma comissão formada por integrantes do IPHAN que se baseou em algumas diretrizes para a escolha, tendo em vista a grande quantidade de fortalezas no território brasileiro. Entre essas normas, buscaram-se os fortes que estabeleceram povoações no país, com exceção das fortificações fluviais a oeste do território nacional, que foram essenciais na delimitação territorial, e também pelos estilos arquitetônicos que marcaram momentos diferentes da história do Brasil. Segue abaixo a ilustração dos fortes selecionados por estado.

Como citado anteriormente, o exército é o gestor da maior quantidade de fortes: os fortes São João e Santa Cruz da Barra (RJ); os fortes Santa Maria, Monte Serrat e São Diego (BA); o Forte Coimbra (MS); o Forte Príncipe da Beira (RO); e o Forte São Batista do Brum (PE).

\section{Considerações finais}

Nos recortes temporais e discursivos abordados, podemos constatar a mudança e adequação do setor cultural do exército no decorrer dos anos e como essa área vem se adaptando e sendo influenciada pelo conceito de cultura na contemporaneidade. Atrelado a isso está o campo do patrimônio cultural, que, de uma área até então não “percebida” pelos 
militares, hoje passou a ter uma série de normativas e começou a ser vista com outro olhar, recebendo uma espécie de novo status, pois foi inserida no plano estratégico que está em voga - criou-se uma diretoria com corpo técnico para tratar não só do patrimônio histórico e cultural, mas de todo o setor de cultura da instituição. O discurso dos militares no que tange ao patrimônio histórico cultural militar oscilou do patrimônio nação, do período getulista, no qual diversas fortificações foram tombadas, à atual política cultural da instituição, que no escopo das suas diretrizes orienta o seu enquadramento ao setor cultural nacional e à aproximação com entidades civis no espectro cultural.

É fundamental salientarmos que essas modificações do setor cultural do exército e, especificamente, do campo do patrimônio passaram por mobilizações também pelo próprio alargamento do conceito que o patrimônio sofreu, porém é notório que hoje o discurso de salvaguarda do patrimônio cultural militar está mais latente, fato exposto na sua atual política cultural, na qual a instituição utiliza o campo para projetar sua imagem. Dois pontos que convergem no discurso em todos os períodos analisados e muito intenso no que tange ao patrimônio são a presença do patriotismo e o sentimento de nacionalidade, que de certa forma norteiam a maneira como os militares tratam o patrimônio. Como já elencado anteriormente, os espaços culturais militares, como as fortificações, estão sob sua gerência e abertos ao público.

Essa mobilização do discurso dos militares em prol da salvaguarda do patrimônio é percebida, por exemplo, nos projetos que a instituição tem elaborado na tentativa de fazer com que a sociedade tenha identificação com o bem patrimonial fortificado. Controvérsias, interesses, relações de poder, imposições, o que se detecta é que os discursos mobilizados no campo do patrimônio militar, na sua temporalidade, exercem o seu controle e operam efeitos materiais, sendo, ao mesmo tempo, selecionados, organizados e redistribuídos por certo número de procedimentos.

A candidatura e a possível chancela a patrimônio mundial da Unesco do conjunto de fortificações brasileiras, de certo modo, dariam outro status a esses bens patrimoniais, porém essa valorização ao patrimônio é mais complexa do que se imagina. O status de patrimônio mundial, fazendo prova de um passado insigne e único, é uma ferramenta simbólica que ajuda a alcançar a notoriedade política num mundo competitivo e também utilizada como fonte de legitimidade política (PEIXOTO, 2002). Nessa perspectiva, o reconhecimento desse conjunto patrimonial pode fazer emergir "conflitos nacionais e locais". Outro entrave que pode ocorrer 
é o fato de, em nome desse "status de patrimônio mundial", o bem cultural se transformar numa causa a serviço das elites dominantes e dos grupos locais de pressão.

\section{Referências Bibliográficas}

ABREU, Regina. Patrimônio Cultural: tensões e disputas de uma ordem discursiva. In: LIMA F.; BELTRÃO, J. Antropologia e patrimônio cultural: diálogos e desafios contemporâneos. Brasília: ABA, 2007.

ANDRADE, Rodrigo Melo Franco de. Rodrigo e o SPHAN: coletânea de textos sobre o patrimônio cultural. Rio de Janeiro: Ministério da Cultura/SPHAN/Pró-Memória, 1987.

ATRIBUIÇÕES DA DPHCEX. http://www.dphcex.eb.mil.br. 2016. Disponível em: <http:/ www.dphcex.eb.mil.br/atribuicoes / >. Acesso em: 10 Jul. 2018.

BERKOWICZ, Clarice. A biblioteca militar e a construção da identidade social do exército no Estado Novo. In: SIMPÓSIO NACIONAL DE HISTÓRIA CONHECIMENTO HISTÓRICO E DIÁLOGO SOCIAL, 27., 2013. Anais... Natal: ANPUH, 2013.

BISCHOFF, James L. A proteção internacional do patrimônio cultural. Revista da Faculdade de Direito da UFRGS, n. 24, 2004.

BOGÉA, Kátia; SCHLEE, Andrey R. Preservação das fortificações do Brasil: um balanço de 80 anos de proteção do IPHAN. Da Cultura, Brasília, ano XVII, n. 29, dez. 2017.

CHUVA, Márcia R. R. Fundando a nação: a representação de um Brasil barroco, moderno e civilizado. Topoi 4, 2003.

Preservação do patrimônio no Brasil: uma perspectiva histórica, ética e política. In: CHUVA, Márcia; NOGUEIRA, Antonio G. Ramos (Orgs.). Patrimônio cultural: políticas e perspectivas de preservação no Brasil. Rio de Janeiro: Mauad X, 2012.

BRASIL. Carta do Recife, 7 abr. 2017. Brasil, 2017. Disponível em: <http://portal.iphan.gov.br/noticias/detalhes/4057/fortificacoes-brasileiras-serao-foco-depolitica-para-incremento-do-turismo-no-brasil >. Acesso em: 21 ago. 2017.

Decreto n. ${ }^{\circ} \mathbf{6 . 7 1 0}, 23$ dez. 2008. Brasil, 2008. Disponível em:

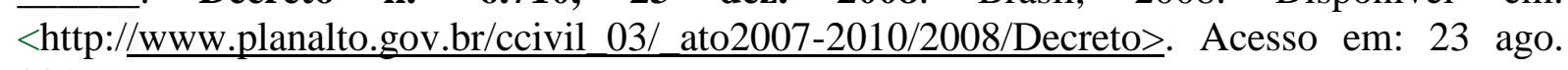
2017.

Decreto n. ${ }^{\circ}$ 99.735, de 27 de novembro de 1990. Brasil, 1990.

Exército Brasileiro. Centro de Comunicação do Exército (CCOMSEx). Verde-Oliva, Brasília, ano 38, n. 208, 2010.

Exército Brasileiro. Portaria n. ${ }^{\circ}$ 615, de 13 de novembro de 2000. Brasil, 2000.

Instituto do Patrimônio Histórico e Artístico Nacional. Brazilian Tentative list 2015

world cultural heritage UNESCO. Disponível em: <http://portal.iphan.gov.br>. Acesso em: 17 ago. 2017.

. Ministério da Defesa. Plano Estratégico do Exército 2016/2019. Boletim Especial

Extraordinário, n. 28, 22 dez. 2014. Disponível em: <www.sgex.eb.mil.br/sistemas/be/copiar.php?codarquivo=1327\&act=bre>. Acesso em: 15 ago. 2017.

Ministério da Defesa. Portaria n. ${ }^{\circ}$ 614, 23 out. 2003. Brasil, 2003. Disponível em:

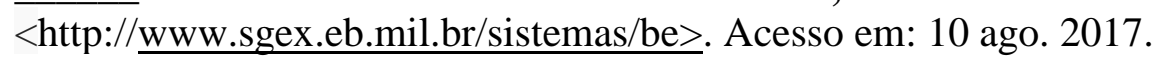

- Ministério da Educação e Cultura. Política Nacional de Cultura. Brasília: Ministério da Educação e Cultura, 1975. 
CARVALHO, José Murilo de. Forças Armadas e política no Brasil. Rio de Janeiro: Jorge Zahar, 2005.

CASTRO, Celso. A invenção do exército brasileiro. Rio de Janeiro: Jorge Zahar, 2002.

FONSECA, Maria Cecília Londres. O patrimônio em processo: trajetória da política federal de preservação no Brasil. 2. ed. Rio de Janeiro: UFRJ/MinC/IPHAN, 2005.

FOUCAULT, Michel. A ordem do discurso. 9. ed. Tradução de Laura Fraga de Almeida Sampaio. São Paulo: Edições Loyola, 2003.

FUNDAÇÃO CULTURAL EXÉRCITO BRASILEIRO (FUNCEB). Estatuto da Fundação Cultural Exército Brasileiro. 2. ${ }^{\circ}$ Ofício de Registro de Pessoas Jurídicas - CRS 505. Registro n. ${ }^{\circ}$ 000078142. Brasil, 2012.

GELLNER, Ernest. Nações e nacionalismo. Lisboa: Gradiva, 1993.

HOBSBAWM, Eric; RANGER, Terence. A invenção das tradições. 4. ed. Rio de Janeiro: Paz e Terra, 2006.

KERSTEN, Márcia Scholz de Andrade. Os rituais do tombamento e a escrita da história: bens tombados no Paraná entre 1938-1990. Curitiba: UFPR, 2000.

MAGALHÃES, Aline Montenegro. Colecionando relíquias: um estudo sobre a Inspetoria de Monumentos Nacionais (1934-1937). Dissertação de mestrado em História social. Rio de Janeiro: UFRJ, IFCS, 2004.

MATTOS, Flávia. A inovação institucional e patrimônio cultural de origem militar no Brasil. Tese (Doutorado)-Universidade Federal do Rio de Janeiro, Rio de Janeiro, 2018.

NAKAMUTA, Adriana. Forte São João e o patrimônio histórico artístico nacional. Dissertação (Mestrado em Arquitetura e Urbanismo)-Universidade Federal de São Carlos, São Carlos, 2009.

ORGANIZAÇÃO DAS NAÇÕES UNIDAS PARA A EDUCAÇÃO, A CIÊNCIA E A CULTURA (UNESCO). Convenção sobre a Proteção do Patrimônio Cultural e Natural. Unesco, 1972.

PEIXOTO, Paulo. A corrida ao status de patrimônio mundial e o mercado urbano de lazer e turismo. Veredas, Coimbra, ano I, n. 1, 2002.

PELEGRINI, Sandra C. A. O patrimônio cultural no discurso e na lei: trajetórias do debate sobre a preservação no Brasil. Patrimônio e Memória, v. 2, n. 2, p. 1-24, 2006.

PEREIRA, Julia Wagner. O tombamento: de instrumento a processo na construção de uma ideia de nação. In: CHUVA, Márcia; NOGUEIRA, Antonio G. Ramos (Orgs.). Patrimônio cultural: políticas e perspectivas de preservação no Brasil. Rio de Janeiro: Mauad X, 2012.

POULOT, Dominique. Uma história do patrimônio no Ocidente. São Paulo: Estação Liberdade, 2009.

REZENDE, Maria José de. A ditadura militar no Brasil: repressão e pretensão de legitimidade: 1964-1984. Londrina: Eduel, 2013.

HOMERO, A. C. F. Muralhas da memória: fortificações, patrimônio e turismo cultural. Caderno Virtual de Turismo. Edição especial: Turismo em fortificações. Rio de Janeiro, v. 1, n. 1, p.08-22, out. 2013.

As muralhas de pedra, canhões, homens de ferro: fortificações do Brasil - 1504-2006. São Paulo: Editora Funceb, 2006.

SILVA, Vanderli M. A construção da política cultural no regime militar: concepções, diretrizes e programas (1974-1978). 143f. Dissertação (Mestrado em Sociologia)Universidade de São Paulo, São Paulo, 2002. 
SOARES, Inês V. Prado. Direito ao patrimônio cultural brasileiro. Belo Horizonte: Fórum, 2009.

TEIXEIRA, Paulo R. O museu histórico do exército e o Forte de Copacabana. Da Cultura, Brasília, ano XV, n. 27, jun. 2016.

TRAJANO, Marcos. Entrevista com o General Chefe do EME. Da Cultura, Brasília, ano IX, n. 15 , jun. 2009.

ZANIRATO, Sílvia. Patrimônio da humanidade: controvérsias conceituais e legais na definição do bem comum. In: ENCONTRO NACIONAL DA ANNPAS. 2010. Disponível em: <http://www.anppas.org.br/encontro5/cd/resumos/>. Acesso em: 10 set. 2017.

Recebido em 10 de setembro de 2018.

Aceito em 11 de outubro de 2018. 